\title{
MODELING RENEWAL TIMES IN AMVRAKIKOS GULF, GREECE
}

\author{
A.I. STAMOU ${ }^{1, *}$ \\ L. LOVERDOU ${ }^{1}$ \\ C. MATSOUKIS ${ }^{1}$ \\ T. ALBANIS ${ }^{2}$ \\ A. GKESOULI ${ }^{1}$
}

Received: $10 / 02 / 12$

Accepted: 27/07/12

\author{
${ }^{1}$ School of Civil Engineering \\ Water Resources and Environmental Engineering \\ National Technical University of Athens \\ Iroon Polytechniou 5, 15780 Athens, Greece \\ ${ }^{2}$ Department of Chemistry, University of loannina \\ University Campus of Ioannina, 45110 Ioannina, Greece
}

*to whom all correspondence should be addressed: e-mail: stamou@central.ntua.gr

\section{ABSTRACT}

The Amvrakikos Gulf, located in the northwest Greece, is one of the largest semi-enclosed embayments being about $40 \mathrm{~km}$ long and $15 \mathrm{~km}$ wide. Water renewal is made via a narrow channel which connects the Gulf with the lonian Sea having a $3.0 \mathrm{~km}$ length, width ranging from 0.8 to 2.0 $\mathrm{km}$ and depth from 2.0 to $13.0 \mathrm{~m}$. The most common terms being used to indicate how fast the water of semi-enclosed coastal embayments is renewed are hydraulic retention time (HRT) and residence time (RT).

A preliminary estimation of HRT and RT is performed via a 3-D integrated model consisting of the hydrodynamic sub-model FLOW-3DL and the water quality sub-model QUAL-3DL. The models involve the 3-D non-steady state continuity, momentum and convection-diffusion equations expressed in layer formulation. A space-staggered computational grid was used and the following conclusions were drawn: (1) The HRT ranges from 1.86 to 2.42 years. (2) The flow rates of Louros and Arachthos rivers, which gush into the Gulf, reduce the HRT by 0.56 years. (3) The effect of the wind on HRT is minor due to the small size of the entrance to the Gulf. (4) The theoretical RT is equal to 3.85 years.

KEYWORDS: water quality models, hydrodynamic models, residence time, hydraulic retention time, semi-closed embayments.

\section{INTRODUCTION}

The Amvrakikos Gulf is located in the north-western coast of Greece; it is one of the largest semienclosed embayments in Greece being about $40 \mathrm{~km}$ long and $15 \mathrm{~km}$ wide. It is characterized as "National Park" by the Greek legislation and it is a part of the wetland of Amvrakikos that is a preserved ecosystem by national and international directives. The wetland is a complex ecosystem consisting of the shallow marine waters of the Gulf, the deltas of Louros and Arachthos rivers that gush into the Gulf, and a lagoon system composed of 3 large lagoons (Logarou, Tsoukalio and Rodia) and over 20 smaller ones, and the largest marsh in Greece (Rodia). The waters of the Amvrakikos Gulf are eutrophic; chlorophyll- $\alpha$ concentration is higher than that of open sea. Generally, river pollution loads, wide seasonal range in temperature (hot and dry summers, mild and rainy winters) and salinity as well as silicate, phosphates and nitrates concentrations make it a stressing environment (Kapsimalis et al., 2005).

Water renewal of semi-enclosed coastal regions is of major importance for their water quality mainly through the supply of oxygen and the removal of pollution. The renewal of the waters of the Amvrakikos Gulf is made exclusively via a narrow channel connecting the Gulf with the Ionian Sea that has a $3.0 \mathrm{~km}$ length, width ranging from 0.8 to $2.0 \mathrm{~km}$ and depth from 2.0 to $13.0 \mathrm{~m}$. This narrow entrance preserves the Gulf from big wave heights; thus, its hydrodynamic regime can be therefore represented by calm wave conditions and small tidal ranges. There are various indicators of how fast 
the water of a semi-enclosed coastal embayment is renewed via transport and mixing; the most common terms being used are hydraulic retention time (HRT) and residence time (RT).

For a tidal flow with period $T$ and half tidal range equal to $\zeta_{0}$ the water elevation $(\zeta)$ and the incoming (or outgoing) flow rate in the Gulf $\left(Q_{G}\right)$, which has a constant surface area equal to $A_{0}$, instant volume at time $t$ equal to $V$ and a tidal average volume equal to $V_{0}$, are calculated by equations (1) and (2), respectively

$\zeta=\zeta_{0} \sin \left(\frac{2 \pi t}{T}\right)$

$Q_{G}=\frac{d V}{d t}=\frac{d\left(A_{0} \zeta\right)}{d t}=\frac{2 \pi A_{0} \zeta_{0}}{T} \cos \left(\frac{2 \pi t}{T}\right)=Q_{0} \cos \left(\frac{2 \pi t}{T}\right)$

where

$$
Q_{0}=\frac{2 \pi A_{0} \zeta_{0}}{T}
$$

HRT can be calculated using only hydrodynamic information from the Gulf by equation (4)

$$
H R T=\frac{V_{0}}{Q_{\text {out }}}=\frac{V_{0} T}{V_{\text {out }}}
$$

where $Q_{\text {out }}$ is the flow rate that exits the Gulf within $T$ and $V_{\text {out }}$ is the volume of water that enters the Gulf during the flood phase, mixes completely with its waters and exits during the ebb phase; this definition is usually referred to as the "volume advection method" (Yin et al., 1998). For the theoretical case of an open completely mixed Gulf $Q_{\text {out }}=Q / \pi$, the theoretical $H R T\left(H R T_{0}\right)$ is calculated by equation (5)

$$
H R T_{0}=\frac{V_{0}}{Q_{\text {out }}}=\frac{V_{0} \pi}{Q_{0}}=\frac{V_{0}}{2 A_{0} \zeta_{0}} \mathrm{~T}
$$

RT can be calculated using hydrodynamic and water quality information from the Gulf assuming that it is initially $(t=0)$ filled with a conservative pollutant whose concentration is equal to $C_{0}$ throughout the Gulf and zero in the region outside the Gulf. The pollutant is subjected to flow convection and mixing and exits the Gulf with concentration equal to $\mathrm{C}_{\mathrm{G}}$. For the theoretical case of completely mixed conditions in the Gulf $\mathrm{C}_{\mathrm{G}}$ can be calculated by equation (6)

$C_{G}=C_{0} e^{-\frac{t}{R T_{0}}}$

where $\mathrm{RT}_{0}$ is the theoretical value of the $\mathrm{RT}$ that is defined as the e-folding time, i.e. the required time to achieve a reduction equal to $36.8 \%(\approx 1 / \mathrm{e})$ of $\mathrm{C}_{0}$.

The importance of renewal times is also recognized in the Water Framework Directive; RT is one of the main factors that characterize surface water bodies according to System B. Based on the requirements of the WFD, Vincent et al. (2002) proposed a pan-European approach in typology to achieve uniform classification system for all national typologies; in this approach RTs are classified in three categories: i) short when RT is equal to days, ii) moderate when RT is equal to weeks and iii) long when RT is counted to months or years.

Renewal times can be used to analyse the variation of renewal for different environment conditions (effect of tidal amplitude, wave current and tidal interaction etc.); additionally, they can be useful for comparison of the effects of several engineering interventions (dredging, structure-building) in a water body and also to define changes in pollutant inputs (Oliveira and Baptista,1997). HRT and RT can be determined with the use of field studies and tracer analyses and/or sophisticated numerical models that can be usually expressed in 2-D depth averaged or 3-D dimensions. In the present work a preliminary estimation of the HRT and RT in Amvrakikos Gulf is performed via the application of a 3-D integrated hydrodynamic - water quality model. 


\section{THE MATHEMATICAL MODEL}

The 3-D integrated model consists of the hydrodynamic sub-model FLOW-3DL and the water quality sub-model QUAL-3DL. FLOW-3DL (Stamou et al., 1999a) involves the 3-D non-steady state continuity and momentum equations, expressed in layer formulation. Using fixed permeable interfaces between layers, the equations of the model are vertically integrated over a depth range $h_{i}$, corresponding to the computational layer " $i$ " of that thickness. The following assumptions are made: (i) the distribution of the pressure $(P)$ is hydrostatic, (ii) the Boussinesq approximation is valid, and (iii) $\mathrm{P}$ at the surface is set equal to the atmospheric (zero). The equations of the model read as follows

$$
\begin{aligned}
& \frac{\partial U}{\partial x}+\frac{\partial V}{\partial y}+\frac{\partial W}{\partial z}=0 \\
& \frac{\partial U}{\partial t}+U \frac{\partial U}{\partial x}+V \frac{\partial U}{\partial y}+W \frac{\partial U}{\partial z}=f \cdot V-g \frac{\partial \zeta}{\partial x}+\frac{\partial}{\partial x}\left(v_{h} \frac{\partial U}{\partial x}\right)+\frac{\partial}{\partial y}\left(v_{h} \frac{\partial U}{\partial y}\right)+\frac{\partial}{\partial z}\left(v_{v} \frac{\partial U}{\partial z}\right) \\
& \frac{\partial V}{\partial t}+U \frac{\partial V}{\partial x}+V \frac{\partial V}{\partial y}+W \frac{\partial W}{\partial z}=-f \cdot U-g \frac{\partial \zeta}{\partial y}+\frac{\partial}{\partial x}\left(v_{h} \frac{\partial V}{\partial x}\right)+\frac{\partial}{\partial y}\left(v_{h} \frac{\partial V}{\partial y}\right)+\frac{\partial}{\partial z}\left(v_{v} \frac{\partial V}{\partial z}\right) \\
& \frac{\partial P}{\partial z}=-\rho \cdot g \text { or } P(z)=-g \cdot \rho \cdot(\zeta-z)
\end{aligned}
$$

The variables of the equations are the layer-averaged velocity components $U, V$ and $W$, along axes $x, y$ and $z$, respectively, of a Cartesian coordinate system, and the free surface elevation $\zeta$. Axis $z$ is taken as positive downward from the sea surface, $v_{h}$ and $v_{v}$ are the horizontal and vertical eddy viscosity coefficients, respectively, $f$ is the Coriolis parameter, $g$ is the gravitational acceleration, and $\rho$ is the water density.

QUAL-3DL (Stamou et al., 1999b) involves the convection-diffusion equation for a conservative pollutant that is written in the following layer formulation

$$
\frac{\partial C}{\partial t}+U \frac{\partial C}{\partial x}+V \frac{\partial C}{\partial y}+W \frac{\partial C}{\partial z}=\frac{\partial}{\partial x}\left(D_{h} \frac{\partial C}{\partial x}\right)+\frac{\partial}{\partial y}\left(D_{h} \frac{\partial C}{\partial y}\right)+\frac{\partial}{\partial z}\left(D_{v} \frac{\partial C}{\partial z}\right)
$$

where $C$ is the layer-averaged pollutant concentrations and $D_{h}$ and $D_{v}$ are the horizontal and vertical diffusion coefficients, respectively.

In the present work, due to the lack of field data (a) the values of the eddy viscosity coefficients were obtained from a previous study (Stamou et al., 2007a and 2007b) and were equal to $v_{h}=1.0 \mathrm{~m}^{2} \mathrm{~s}^{-1}$ and $v_{v}=0.005 \mathrm{~m}^{2} \mathrm{~s}^{-1}$ and (b) the following conservative values for the diffusion coefficients were used: $D_{h}=0.5 \mathrm{~m}^{2} \mathrm{~s}^{-1}$ and $D_{\mathrm{v}}=0.005 \mathrm{~m}^{2} \mathrm{~s}^{-1}$.

The following calculation procedure is applied:

1) The distribution of pressure $P$ is determined from equation (10).

2) The horizontal velocities $U$ and $V$ are calculated by equations (8) and (9), respectively.

3) The vertical velocities $W$ are deduced by solving equation (7) successively for each layer starting from the bottom, where the boundary condition $W=0$ is used. At the surface, equation (7) can be written as a linearized kinematic boundary condition, whereby the surface elevation can be deduced; subscript ' $\zeta$ ' denotes values at the surface layer

$$
\frac{\partial \zeta}{\partial t}+\frac{\partial \zeta}{\partial x} U_{\zeta}+\frac{\partial \zeta}{\partial y} V_{\zeta}=W_{\zeta}
$$

4) The convection-diffusion equation (11) is solved in a transient mode to determine the distribution of $C$ within the Gulf assuming that at $t=0$ the Gulf is filled with a conservative pollutant whose concentration is equal to $C_{0}=1.0 \mathrm{ppm}$ throughout the Gulf and zero in the region outside the Gulf.

5) Qut is calculated from computed flow velocities in the entrance of the Gulf and HRT is derived by equation (4); moreover, $Q_{\text {out }}$ values are compared with theoretical values of $Q_{G}$.

6) RT is determined by equation (6) and the calculated values of $\mathrm{C}$. 


\section{APPLICATION OF THE MODEL}

The geometrical characteristics of the Gulf are the following: $A_{0}=480 \mathrm{~km}^{2}, V_{0}=10.8 \mathrm{~km}^{3}$, average water depth $h_{0}=22.5 \mathrm{~m}$ and maximum water depth $\mathrm{h}_{\max }=62.0 \mathrm{~m}$. A space-staggered computational grid was used that covers the area of the Amvrakikos Gulf and a small part of the Ionian Sea.

In Figure 1 the boundaries of the computational grid are shown. The grid consisted of $84 \times 50$ control volumes with constant resolution equal to $500.0 \mathrm{~m}$ and 7 layers in the z-direction with the following depths: $0.0-1.0 \mathrm{~m}, 1.0-3.0 \mathrm{~m}, 3.0-6.0 \mathrm{~m}, 6.0-13.0 \mathrm{~m}, 13.0-24.0 \mathrm{~m}, 24.0-40.0 \mathrm{~m}$ and $40.0-62.0 \mathrm{~m}$; moreover, it involved an "open-sea" boundary at which equation (1) was used as "tidal condition" and it was assumed that the gradient of the velocity component normal to the boundary is zero. This grid was selected after a series of preliminary grid independence tests.

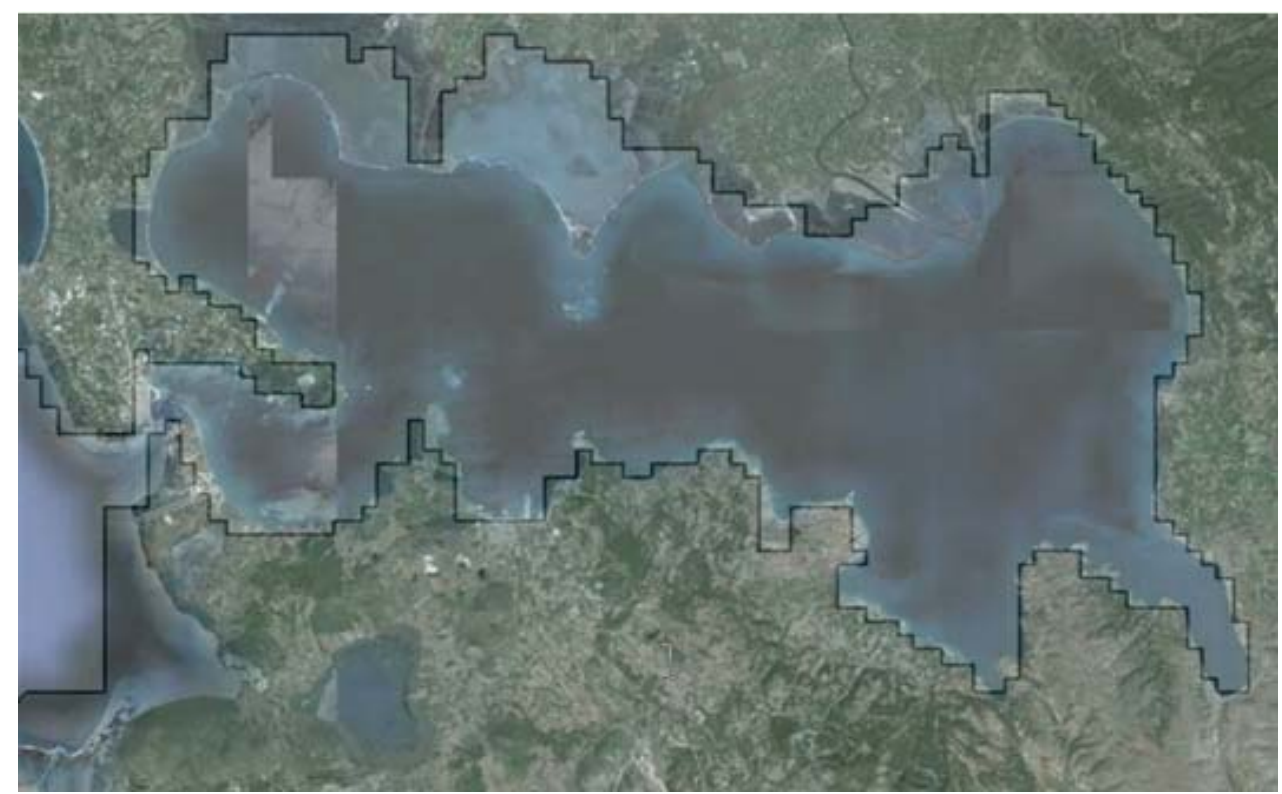

Figure 1. The area of study and the boundaries of the numerical grid

The characteristics of the main scenarios of computations are shown in Table 1. In scenarios S1, S2 and S3 the effect of the tidal range is examined. Scenario S4 deals with the tidal calculation for the mean tidal range that includes the effect of river discharges. Scenario S5 refers to a combined wind/tidal driven calculation for the mean tidal range that takes into account the average wind characteristics; the direction and the velocity of the wind are assumed to be constant and equal to their average values throughout the computational domain and for the total computation time. Scenario $\mathrm{S} 6$ is a combined calculation that takes into account all the driving forces of the flow field.

Table 1. Characteristics of the scenarios of calculations

\begin{tabular}{ccccc}
\hline $\begin{array}{c}\text { Scenarios } \\
(-)\end{array}$ & $\begin{array}{c}\boldsymbol{\zeta}_{0} \\
(\mathbf{m})\end{array}$ & $\begin{array}{c}\text { Wind } \\
\text { (direction- } \\
\text { speed) }\end{array}$ & $\begin{array}{c}\text { Arachthos } \\
\text { flow rate } \\
\left(\mathbf{m}^{3} \mathbf{s}^{-1}\right)\end{array}$ & $\begin{array}{c}\text { Louros } \\
\text { flow rate } \\
\left(\mathbf{m}^{3} \mathbf{s}^{-1}\right)\end{array}$ \\
\hline S1 & 0.025 (average) & - & - & - \\
S2 & 0.005 (minimum) & - & - & - \\
S3 & 0.145 (maximum) & - & - & - \\
S4 & 0.025 & - & 66.4 & 19.3 \\
S5 & 0.025 & $\mathrm{NE}-4.3 \mathrm{~m} \mathrm{~s}^{-1}$ & - & - \\
S6 & 0.025 & $\mathrm{NE}-4.3 \mathrm{~m} \mathrm{~s}^{-1}$ & 66.4 & 19.3 \\
\hline
\end{tabular}




\section{RESULTS AND DISCUSSION}

In Figures 2 and 3 the flow fields of the $1^{\text {st }}$ (depth=0.0-1.0 m) and $4^{\text {th }}$ layer (depth-6.0-13.0 m) for scenarios S4 and S6 are shown, respectively. Figure 4 shows the variation of the flow rate with time (t) in the entrance of the Gulf for all scenarios. In Table 2 the values of $Q_{\text {out }}$ and HRT are shown.
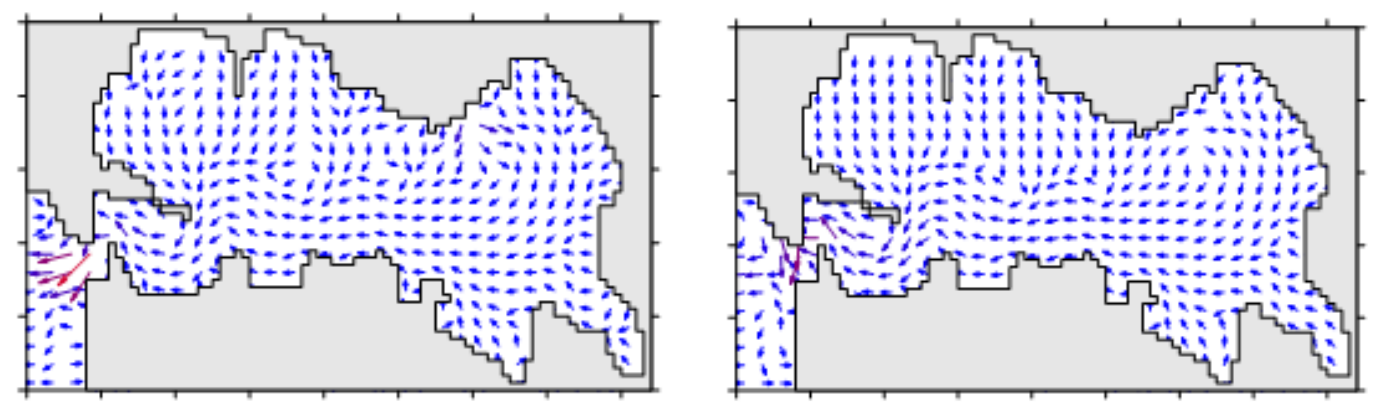

Figure 2. Velocity vectors of the $1^{\text {st }}$ and $4^{\text {th }}$ layer for scenario S4
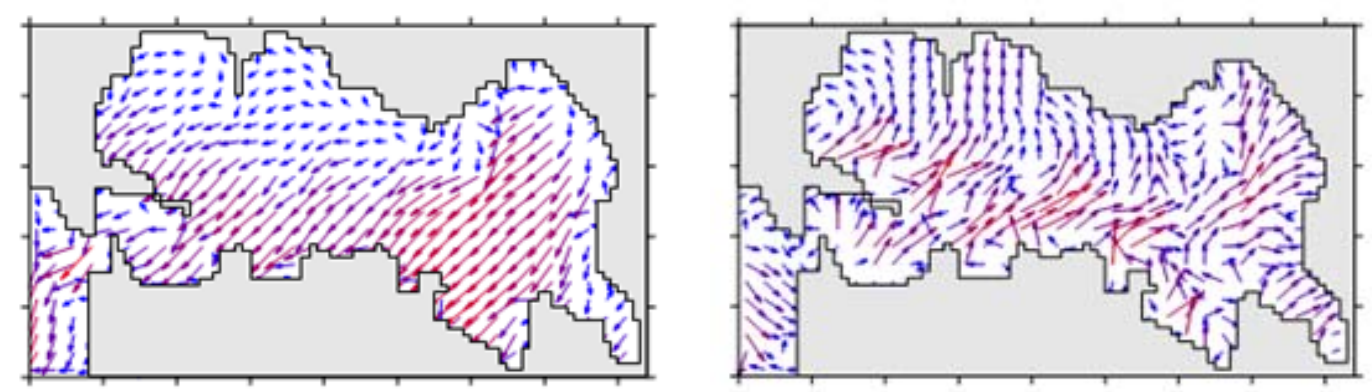

Figure 3. Velocity vectors of the $1^{\text {st }}$ and $4^{\text {th }}$ layer for scenario S6

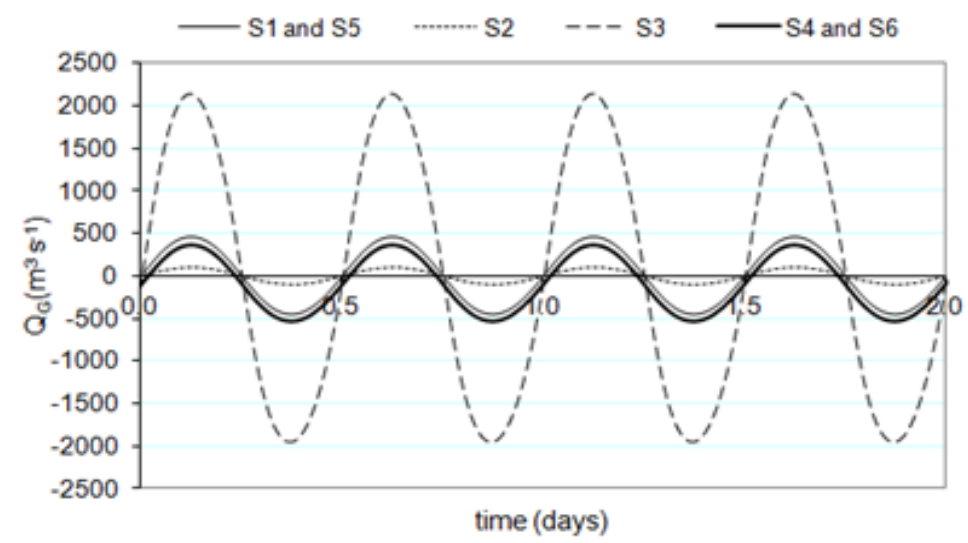

Figure 4. Variation of the flow rate in the entrance of the Gulf for all scenarios

Table 2. Calculated exit flows and HRT for all scenarios

\begin{tabular}{cccc}
\hline $\begin{array}{c}\text { Scenarios } \\
(-)\end{array}$ & $\begin{array}{c}\boldsymbol{\zeta}_{\mathbf{0}} \\
(\mathbf{m})\end{array}$ & $\begin{array}{c}\mathbf{Q}_{\text {out }} \\
\left(\mathbf{m}^{3} \mathbf{s}^{-1}\right)\end{array}$ & $\begin{array}{c}\text { HRT } \\
(\text { years })\end{array}$ \\
\hline S1 & 0.025 & 142 & 2.42 \\
\hline S2 & 0.005 & 30 & 11.39 \\
\hline S3 & 0.145 & 654 & 0.52 \\
\hline S4 & 0.025 & 184 & 1.86 \\
\hline S5 & 0.025 & 142 & 2.42 \\
\hline S6 & 0.025 & 184 & 1.86 \\
\hline
\end{tabular}


The flow field for scenario S4 in Figure 2 shows a typical (almost) unidirectional tidal driven flow behaviour; in the Gulf maximum velocities are up to $0.03 \mathrm{~m} \mathrm{~s}^{-1}$ in the surface and $0.02 \mathrm{~m} \mathrm{~s}^{-1}$ in the forth layer. Figure 3 depicts that the presence of wind in scenario S6 affects the flow that shows the typical two-layer structure of enclosed wind driven flows; in the Gulf maximum velocities are up to $0.08 \mathrm{~m} \mathrm{~s}^{-1}$ in the surface and $0.06 \mathrm{~m} \mathrm{~s}^{-1}$ in the forth layer. The maximum velocities for both scenarios S4 and S6 are approximately equal to $0.16 \mathrm{~m} \mathrm{~s}^{-1}$ and are observed in the region of the entrance.

Figure 4 depicts that maximum values of $Q_{G}\left(Q_{G, \max }\right)$ are equal to $94.6 \mathrm{~m}^{3} \mathrm{~s}^{-1}, 446.5 \mathrm{~m}^{3} \mathrm{~s}^{-1}$ and $2053.7 \mathrm{~m}^{3} \mathrm{~s}^{-1}$ for the tidal ranges $0.005 \mathrm{~m}, 0.025 \mathrm{~m}$ and $0.145 \mathrm{~m}$, respectively; the corresponding theoretical values for open gulfs $\left(Q_{0}\right)$ are equal to $349.2 \mathrm{~m}^{3} \mathrm{~s}^{-1}, 1746.2 \mathrm{~m}^{3} \mathrm{~s}^{-1}$ and $10127.9 \mathrm{~m}^{3} \mathrm{~s}^{-1}$ for the tidal ranges $0.005 \mathrm{~m}, 0.025 \mathrm{~m}$ and $0.145 \mathrm{~m}$, respectively. Generally, due to the small dimensions of the entrance, maximum values of $\mathrm{Q}_{\mathrm{G}}$ are equal to $27.1 \%, 25.6 \%$ and $20.3 \%$ of their theoretical values, respectively, for the tidal ranges $0.005 \mathrm{~m}, 0.025 \mathrm{~m}$ and $0.145 \mathrm{~m}$, respectively; i.e. the ratio $\mathrm{Q}_{\mathrm{G}, \max } / \mathrm{Q}_{0}$ decreases with increasing tidal range. This remark is in accordance with the findings of Tsoukala and Moutzouris (2009) who observed that the height of the transmission coefficient of a sinusoidal wave via a flushing culvert decreases with increasing incident wave height.

Table 2 shows that HRT for the average tidal range ranges from 1.86 to 2.42 years. The effect of the flow rates originating from the rivers Louros and Arachthos on HRT is relatively important and contributes to the reduction of the HRT by 0.56 years or $23 \%$. The effect of the wind on HRT is negligible; this behaviour was expected and is due to the small size of the entrance to the Gulf that prohibits the exchange of significant water masses with the lonian Sea. However, the wind driven flow field for scenario S6 is characterised by relatively high velocities and shear between the two layers that enhances mixing of the pollutant in the Gulf thus accelerating the exit of the pollutant from the Gulf and decreasing RT.

In Figure 5 the variation of the concentration of the pollutant in the entrance of the Gulf with time is shown together with the best fit exponential curve that has the following form

$$
C_{G}=C_{0} e^{-0.26 t}
$$

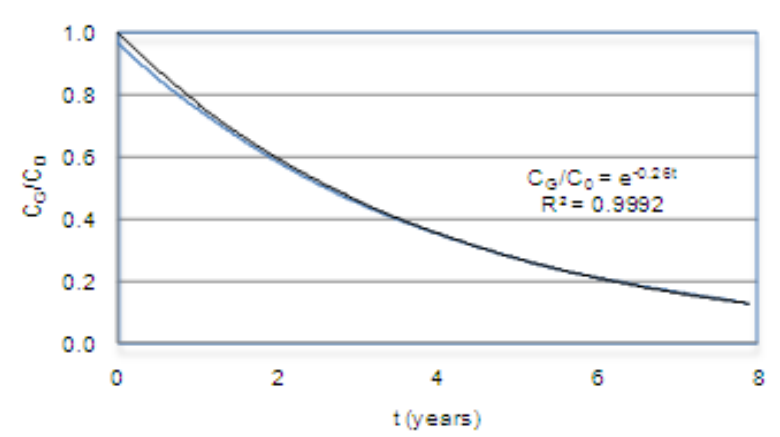

Figure 5. Distribution of the average RT in the Gulf for scenario S6

Figure 5 depicts that concentration values almost coincide with the best fit exponential curve; the correlation coefficient is equal to 0.9992 . The theoretical RT in the Gulf is calculated by equation (6) equal to $R T_{0}=1 / 0.26=3.85$ years, i.e. $R T_{0} / H R T_{0}=3.85 / 1.86=2.07$.

\section{CONCLUSIONS}

From the application of a 3-D integrated model in Amvrakikos Gulf the following preliminary estimations are made regarding the hydraulic retention time (HRT) and residence time (RT) in the Gulf: (1) The HRT ranges from 1.86 years to 2.42 years. (2) The effect of the flow rates from rivers Louros and Arachthos on HRT is relatively important and contributes to the reduction of the HRT by 0.56 years or $23 \%$. (3) The effect of the wind on HRT is minor due to the small size of the entrance to the Gulf. (4) The theoretical RT in the Gulf is equal to 3.85 years, i.e. almost twice the HRT. 


\section{REFERENCES}

1. Kapsimalis V., Pavlakis P., Poulos S.E., Alexandri S., Tziavos C., Sioulas A., Filippas D. and Lykousis V. (2005), Internal structure and evolution of the late quaternary sequence in a shallow embayment: The Amvrakikos Gulf, NW Greece, Marine Geology, 222-223, 339-418.

2. Oliveira A. and Baptista A.M. (1997), Diagnostic modeling of residence time in estuaries, Water Resources Research, 33(8), 1935-1946.

3. Stamou A.I., Noutsopoulos C., Pipilis K.G., Gavalaki E. and Andreadakis A. (1999a), Hydrodynamic and water quality modelling of Southern Evoikos Gulf - Greece, Global Nest the International Journal, 1(2), 131-141.

4. Stamou A.I., Memos K. and Pipilis K. (1999b), Mathematical modelling of thermal discharges in coastal regions, 28th IAHR Congress, Graz, Austria.

5. Stamou A.I., Memos C.D. and Spanoudaki K. (2007a), Estimating water renewal time in semienclosed coastal areas with complicated geometry using a hydrodynamic model, Journal of Coastal Research, 50, 282-286.

6. Stamou A.I., Memos C.D. and Kapetanaki M.E. (2007b), Modelling water renewal in a coastal embayment, Proceedings of the ICE - Maritime Engineering, 160(MA3), 93-104.

7. Tsoukala, V. K. and Moutzouris, C. I. (2009), Wave transmission in harbors through flushing culverts, Ocean Engineering, 36(6-7), 434-445.

8. Vincent C., Heinrich H., Edwards A., Nygaard K. and Haythornthwaite J. (2002), Guidance on typology, reference conditions and classification systems for transitional and coastal waters. Produced by: CIS Working Group 2.4 (Coast), Common Implementation Strategy of the Water Framework Directive, European Commission, 119.

9. Yin J., Falconer R.A., Pipilis K. and Stamou A.I. (1998), Flow characteristics and flushing processes in marinas and coastal embayments, Proceedings of the 1st Int. Conf. on Maritime Engineering and Ports, Genoa, 87-98. 